\title{
Vertical distribution and the role of physical processes in the feeding dynamics of two larval sciaenids Sciaenops ocellatus and Cynoscion nebulosus
}

\author{
G. Joan Holt*, Scott A. Holt \\ University of Texas at Austin Marine Science Institute, 750 Channel View Drive, Port Aransas, Texas 78373, USA
}

\begin{abstract}
Red drum Sciaenops ocellatus and spotted seatrout Cynoscion nebulosus larvae were collected using plankton and benthic-sled tows every $2 \mathrm{~h}$ for $26 \mathrm{~h}$ on 4 separate dates in late August to early October 1990 in Aransas Bay, Texas, USA. Gut contents and gut fullness were evaluated to determine if feeding was randomly distributed over depth and time, and to compare feeding between the 2 species. Calanoid copepods were the dominant prey over all size-classes of red drum larvae. Copepod nauplii, bivalve and barnacle larvae were important for small red drum, while calanoid copepods, dinoflagellates and soft-bodied organisms were important in the diets of large red drum larvae. Calanoid copepods and bivalve larvae were the most important food iterns for spotted seatrout; gastropod veligers and copepod nauplii were also important prey. Gape size was positively correlated with standard length in both species. Mean prey size increased with gape width but there was wide variation in prey size at any given gape width. Small $(<3.0 \mathrm{ram})$ and medium $(3.0$ to $4.5 \mathrm{~mm})$ fish of both species fed on similar prey but large $(>4.5 \mathrm{~mm})$ fish had distinct diets. Similar numbers of larvae were collected in surface and bottom waters $(6 \mathrm{~m})$ during the night, but during the day more larvae were collected in bottom waters. Larvae of both species fed primarily during daylight hours. Feeding extended $2 \mathrm{~h}$ later in the evening for spotted seatrout than for red drum. There was no significant relationship between current speed and gut fullness in spotted seatrout or in red drum. Larvae were very successful at feeding under all conditions with little indication that vertical distribution was associated with feeding success. Transit periods through well-mixed tidal inlets may provide excellent feeding opportunities, as well as a route to transport larvae to essential nursery habitats.
\end{abstract}

KEY WORDS: Larval transport · Recruitment - Microzooplankton prey · Gut contents · Diurnal migration $\cdot$ Red drum $\cdot$ Spotted seatrout - Tides

\section{INTRODUCTION}

It is generally recognized that recruitment success is largely established during the egg and larval period (Leggett \& DeBlois 1994). Recruitment variability has been correlated to both abiotic and biotic events. Predation and starvation are often sited as principal sources of mortality in larval fishes (Houde 1987), but transport to or away from favorable areas is also crucial to marine fish larvae (Hjort 1914). Physical and biolog-

\footnotetext{
•E-mail: joan@utmsi.utexas.edu
}

ical processes often interact to affect transport processes. Feeding success is a major factor regulating growth rate which, in turn, influences starvation and predation rates through increased larval size (i.e. the 'bigger-is-better' hypothesis, Litvak \& Leggett 1992), and facilitates transport through increased swimming ability and buoyancy regulation. The period of transport through tidal inlets may be critical for estuarinedependent marine species as they pass from offshore spawning sites to estuarine nursery areas (Lyczkowski-Shultz et al. 1990). Little information exists on feeding activity of larvae during this critical transport phase or on its effect on recruitment success. 
Two sciaenids, red drum Sciaenops ocellatus and spotted seatrout Cynoscion nebulosus, have overlapping spawning seasons in the northwestern Gulf of Mexico but different life histories. Spotted seatrout spawn from March through October and red drum from August through October in South Texas, USA (Holt et al. 1988). Red drum adults live and spawn in the Gulf of Mexico and their eggs and larvae are transported through tidal passes into estuaries where larvae recruit to seagrass habitat. Spotted seatrout, on the other hand, spawn in bays and estuaries and small larvae $(4+\mathrm{mm}$ standard length [SL]) are found in seagrass beds, often co-occurring with young red drum of similar size (Rooker et al. 1998). Transport into and within the bay in both species may be mediated by the vertical position of the larvae in the water column.

Vertical movement in fish larvae may result from a response to light, temperature, prey distributions (Boehlert \& Mundy 1988) or tidal currents (Smith \& Stoner 1993). Holt et al. (1989) found a significantly greater proportion of red drum larvae in surface samples on flood than on ebb tides in a tidal inlet. Thus vertical movement in red drum larvae appears to be cued by tidal currents, suggesting that some form of behavioral response to tidal cycles facilitates their transport through the inlet into the estuarine nursery. Boehlert \& Mundy (1988) suggested that fish could use tidal stream transport both for movement into an estuary and for maintenance within an estuary. Spotted seatrout may therefore utilize something similar to tidal stream transport to avoid seaward transport that might flush the planktonic larvae from the bay, though little is known about their vertical distribution in estuaries.

Vertical migration in response to prey distribution has been suggested for herring larvae (Fortier \& Leggett 1983, Munk et al.1989). The latter concluded that herring larvae migrate to depths to avoid predation but where light remains sufficient for feeding. Feeding-related movements could play a role in immigration to nursery sites, in concert with or opposed to tidal stream transport. Transport processes may also influence feeding conditions, especially near shore and in inlets where tidal currents produce turbulent mixing Tidally well-mixed regions can provide superior feeding environments compared to stratified regions due to turbulence-enhanced encounter rates between predator and prey (Muelbert et al. 1994).

This study examined diel food habits of larvae passing by a single location in a tidal inlet over both flood and ebb tides in a Eularian perspective. The objectives of the study were to describe and compare the feeding dynamics of red drum and spotted seatrout larvae within a tidal inlet, and to detemine the effects of diel cycle, depth, and current speed on feeding success.
The relationship of feeding activity and vertical distribution of larvae of both species is discussed in light of potential effects on larval immigration and recruitment to nursery areas.

\section{STUDY AREA AND METHODS}

Red drum and spotted seatrout larvae were collected on 4 separate dates in late August to early October, 1990 from a single site in Lydia Ann Channel, 1 of 3 tributary channels of the Aransas Pass tidal inlet

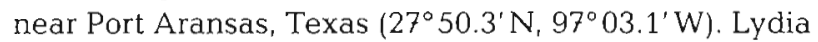
Ann Channel connects Aransas Bay with the Gulf of Mexico. Water depth at the site is approximately $6 \mathrm{~m}$ and channel width averages $300 \mathrm{~m}$. Samples were taken on the surface and bottom of the channel every $2 \mathrm{~h}$ for $26 \mathrm{~h}$. Surface collections were made with a $1 \mathrm{~m}$, $500 \mu \mathrm{m}$ mesh plankton net $\left(0.78 \mathrm{~m}^{2}\right.$ surface area) and bottom collections were made with a similar size net mounted on an epibenthic sled set to fish $20 \mathrm{~cm}$ off the bottom. All tows were made into the current. To avoid contaminating the bottom sample, the boat was backed down on the net and the sled was lifted straight up from the bottom. Both nets were equipped with netmounted flow meters to record water volume filtered. Larval abundance was converted to density and expressed as number per $100 \mathrm{~m}^{3}$.

Currents were measured at the site with moored surface and bottom $(5 \mathrm{~m})$ current meters. Vertical profiles of temperature and salinity were measured each hour with a SeaBird SB19 CTD. Values taken from the 1 and $5 \mathrm{~m}$ depths were used to represent surface and bottom temperature and salinity.

Tides on the central Texas coast are mixed, but principally diurnal (Smith 1979). The fortnightly transition from tropic to equatorial tides produces an alternating pattern of diurnal and semi- diurnal tidal cycles. The strongest ebb and flood currents in the tidal inlet are typically 60 to $70 \mathrm{~cm} \mathrm{~s}^{-1}$ under diurnal tides whereas ebb and flood currents during semi-diurnal tides range from 20 to $40 \mathrm{~cm} \mathrm{~s}^{-1}$ (Smith 1979). Four suites of samples were taken, 2 during periods of diurnal tides and 2 during periods of semi-diurnal tides, over a 6 wk period from late August through early October (Fig. 1). A sample suite consisted of triplicate surface and bottom plankton tows taken every $2 \mathrm{~h}$ beginning at slack tide and continuing for a $26 \mathrm{~h}$ period. During diurnal tides the $26 \mathrm{~h}$ collecting period encompassed 1 full tidal cycle. The sampling period for semi-diurnal tides encompassed at least 1 flood and 1 ebb tide and due to tidal inequalities, often included extended periods of near slack tjdes. Each set of triplicate surface and bottom samples was completed in about $45 \mathrm{~min}$. Surface and bottom collections were alternated within a set. 


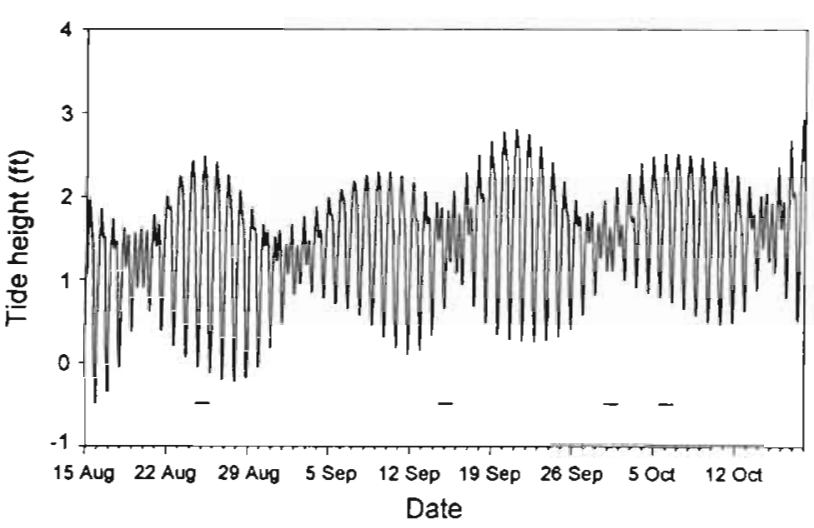

Fig. 1. Predicted tides for the Aransas Pass over the sampling period showing the oscillation between diurnal and semidiurnal tides. Four bars under the plot indicate the dates (and tidal phase) when collections were made

Larvae were preserved (within 5 to $10 \mathrm{~min}$ of capture) in $5 \%$ formalin and later transferred to $95 \%$ ethanol. SL, gape width (measured from the ventral aspect as the distance between the posterior mandible tips), and gut fullness were measured on all larvae (1999 red drum, 1.32 to $7.60 \mathrm{~mm} \mathrm{SL}$ and 1205 spotted seatrout, 1.38 to $7.23 \mathrm{~mm} \mathrm{SL}$ ) to the nearest $0.01 \mathrm{~mm}$ using SigmaScan image analysis software. Measurements were made with a Summasketch digitizing pad as larvae were viewed through a drawing tube on a stereo microscope. To measure gut fullness, the size of the gut was traced with a larva laying on its side. SigmaScan translated this irregular shape into total area of the gut $(\mathrm{G})$. The same procedure was used to measure the area filled with prey $(\mathrm{p})$; percent gut fullness was determined as $\mathrm{p} / \mathrm{g} \times 100$. There was no significant difference $(p<0.05)$ in total area of the gut $(G)$ between full and partially full guts.

Gut contents were identified from 156 red drum, 1.49 to $7.60 \mathrm{~mm}$ (preserved) $\mathrm{SL}$, and 129 spotted seatrout larvae, 1.38 to $7.23 \mathrm{~mm}$ (preserved) SL. The 285 larvae were selected from all 4 trips to include possible temporal (hour and date) and vertical variability, and cooccurrence of both species. The gastrointestinal tract, from the esophagus to the anus, was excised and transferred to a drop of water and teased apart to remove contents. Prey items were identified to the lowest taxon possible, counted and measured across the shortest body axis. Soft-bodied organisms were not identifiable (may have included flatworms, rotifers, polychaetes, protozoans, and tentacles) but had a definite size. Larvae were grouped into 3 size categories (small <3.0, medium 3.0 to 4.5 , and large $>4.5 \mathrm{~mm} \mathrm{SL}$ ) for interspecific and intraspecific diet comparisons. Percent frequency of occurrence $(\% \mathrm{~F})$ and percent of total number $(\% \mathrm{~N})$ of diet items for fish larvae in each size-class were calculated; an index of relative importance of each prey was calculated as $\mathrm{F} \times \mathrm{N}$ (Steen \& LaRoche 1983). Diet overlap between similar sizeclasses of red drum and spotted seatrout, and among size-classes within each species were measured using the Schoener index (Schoener 1968). The index has a scale from 0 (no overlap) to 100 (complete overlap between pairs). Overlap indices $>60 \%$ were considered to be 'high' and $<40 \%$ to be 'low'.

The effect of position in the water column (i.e. surface or bottom) and day verses night on percent gut fullness were tested with 2-way ANOVA using a randomized block design. The collection date was used as a blocking factor to account for potential differences in feeding conditions between collections. Percent gut fullness was transformed by arcsine square root prior to all analyses. We used data collected from 08:00 to 20:00 $\mathrm{h}$ for the day and 22:00 to 06:00 $\mathrm{h}$ for the night samples. Only data from the first 2 sampling dates were used for spotted seatrout since very few spotted seatrout larvae $(<1 \%$ of total) were collected on the last 2 sampling dates.

The influence of current speed on gut fullness was examined through regression analysis. Mean gut fullness of larvae from each bi-hourly collection was regressed against the corresponding hourly mean current speed, for each species. Only those periods when the larvae were feeding (hours when mean gut fullness averaged $>30 \%$, see below) were included in the analysis. That excluded larvae collected at 00:00, 02:00, 04:00 and 06:00 $\mathrm{h}$ for red drum and 02:00, 04:00, and 06:00 $\mathrm{h}$ for spotted seatrout. We examined the potential for a domed shaped feeding response to turbulence (Mackenzie et al. 1994) that would be generated by tidal currents (Fox et al. 1999) by fitting a quadratic equation to the data.

\section{RESULTS}

The 4 collection dates included 2 diurnal and 2 semidiurnal tidal periods (Fig. 1). Maximum current speed reached $77 \mathrm{~cm} \mathrm{~s}^{-1}$ and averaged $39.5 \mathrm{~cm} \mathrm{~s}^{-1}$ during diurnal tides, while maximum current was $59 \mathrm{~cm} \mathrm{~s}^{-1}$ during the semi-diurnals, averaging $22.3 \mathrm{~cm} \mathrm{~s}^{-1}$. Water temperatures ranged from 23.8 to $31.1^{\circ} \mathrm{C}$ and were lowest during the middle of the study due to the passage of a polar frontal system. Salinities ranged from 26.2 to $36.1 \mathrm{ppt}$ and were relatively similar within a collection period. Turbulent flow in the inlet precluded any stratification within the water column and surface to bottom temperatures and salinities were essentially uniform throughout the study.

The highest densities of red drum and spotted seatrout larvae were taken in bottom collections. Similar 
densities of larvae were collected in surface and bottom waters $(6 \mathrm{~m})$ during the night $(22: 00$ to $06: 00 \mathrm{~h})$, but during the day more larvae were collected from the bottom than the surface except for red drum at 18:00 $\mathrm{h}$ (Table 1).

\section{Types of prey}

The majority of food items dissected from fish guts were small (10 to $300 \mu \mathrm{m}$ in width) and included vari- ous life stages of copepods, bivalves, dinoflagellates, barnacle nauplii, and gastropod veligers. Calanoid copepods were the most important prey for both species, but the types of prey eaten were highly variable and changed as a function of fish size (Tables $2 \& 3$ ).

Highest prey overlap between red drum and spotted seatrout was found among small and medium-sized larvae (Table 4). There was high prey overlap in the diets of small red drum larvae collected from surface and bottom but only moderate overlap for medium and larger size- classes (Table 5A). Diet of the smallest red

Table 1. Densities (no. $100 \mathrm{~m}^{-3}$ ) of red drum Sciaenops ocellatus and spotted seatrout Cynoscion nebulosus larvae taken from surface and bottom $(6 \mathrm{~m})$ collections every $2 \mathrm{~h}$ from 00:00 (midnight) to 22:00 h, averaged over 4 sampling dates from August 24 to October 6, 1990

\begin{tabular}{|c|c|c|c|c|c|c|c|c|c|c|c|c|c|}
\hline & Time (h) & $00: 00$ & $02: 00$ & $04: 00$ & $06: 00$ & $08: 00$ & $10: 00$ & $12: 00$ & $14: 00$ & $16: 00$ & $18: 00$ & $20: 00$ & $22: 00$ \\
\hline \multicolumn{14}{|c|}{ Red drum } \\
\hline Surface & & 1.64 & 1.51 & 1.72 & 1.22 & 0.11 & 0.15 & 0.26 & 0.18 & 0.41 & 2.46 & 2.85 & 11.50 \\
\hline Bottom & & 2.62 & 1.17 & 1.42 & 1.53 & 2.18 & 0.79 & 2.68 & 7.78 & 2.68 & 1.83 & 3.32 & 14.00 \\
\hline \multicolumn{14}{|c|}{ Spotted seatrout } \\
\hline Surface & & 2.27 & 2.28 & 2.15 & 2.21 & 0.87 & 0.46 & 0.24 & 0.14 & 0.13 & 0.36 & 1.20 & 2.56 \\
\hline Bottom & & 1.84 & 0.87 & 2.15 & 2.12 & 2.53 & 1.38 & 2.51 & 4.70 & 0.82 & 0.59 & 2.15 & 4.71 \\
\hline
\end{tabular}

Table 2. Food items making up more than $1 \%$ of the total items $(N)$ in the guts of red drum larvae by size class. Food items are listed in descending order of overall importance. (F) Frequency of occurrence and (IRI) index of relative importance $=\% \mathrm{~N} \times \% \mathrm{~F}$

\begin{tabular}{|c|c|c|c|c|c|c|c|c|c|c|}
\hline \multirow{2}{*}{$\begin{array}{l}\text { Size class (mm SL) } \\
\text { Food Items }\end{array}$} & \multicolumn{3}{|c|}{$<2.99$} & \multicolumn{3}{|c|}{$3.0<\mathrm{SL}<4.5$} & \multicolumn{3}{|c|}{$>4.5$} & \multirow[t]{2}{*}{ Sum of IRI } \\
\hline & $\% N$ & $\% \mathrm{~F}$ & IRI & $\% \mathrm{~N}$ & $\% \mathrm{~F}$ & IRI & $\% \mathrm{~N}$ & $\% F$ & IRI & \\
\hline Calanoid copepod & 3.97 & 12.96 & 51.48 & 23.12 & 54.05 & 1249.49 & 27.27 & 52.17 & 1422.92 & 2723.89 \\
\hline Copepod nauplius & 20.94 & 48.15 & 1008.16 & 9.05 & 27.03 & 244.47 & 2.48 & 4.35 & 10.78 & 1263.40 \\
\hline Soft-bodied organism ${ }^{\mathrm{a}}$ & 1.81 & 5.56 & 10.03 & 6.03 & 21.62 & 130.38 & 16.53 & 30.43 & 503.05 & 643.46 \\
\hline Dinoflagellate & 5.05 & 14.81 & 74.88 & 2.51 & 13.51 & 33.95 & 14.05 & 21.74 & 305.43 & 414.26 \\
\hline Bivalve larvae & 11.55 & 31.48 & 363.68 & 3.02 & 10.81 & 32.60 & & & & 396.28 \\
\hline Invertebrate egg/cyst ${ }^{\mathrm{b}}$ & 3.25 & 5.56 & 18.05 & 17.59 & 16.22 & 285.21 & & & & 303.26 \\
\hline Barnacle nauplius & 10.83 & 22.22 & 240.67 & 3.02 & 10.81 & 32.60 & & & & 273.27 \\
\hline Foraminifera & 6.86 & 14.81 & 101.62 & 5.53 & 21.62 & 119.52 & 7.44 & 4.35 & 32.34 & 253.47 \\
\hline Unicellular algae & 3.25 & 11.11 & 36.10 & 1.51 & 8.11 & 12.22 & 4.96 & 21.74 & 107.80 & 156.12 \\
\hline Copepod metanauplius & 4.69 & 12.96 & 60.84 & 4.02 & 13.51 & 54.33 & & & & 115.16 \\
\hline Barnacle cypris & 3.97 & 12.96 & 51.48 & 1.51 & 5.41 & 8.15 & 4.13 & 13.04 & 53.90 & 113.52 \\
\hline Cyclopoid copepod & & & & 4.02 & 13.51 & 54.33 & 3.31 & 17.39 & 57.49 & 111.82 \\
\hline Gastropod viliger & 4.33 & 14.81 & 64.18 & 1.51 & 8.11 & 12.22 & & & & 76.40 \\
\hline Tintinnid & 1.81 & 5.56 & 10.03 & & & & 3.31 & 13.04 & 43.12 & 53.15 \\
\hline Protozoa & 1.44 & 5.56 & 8.02 & 4.52 & 8.11 & 36.67 & & & & 44.69 \\
\hline Copepodite & 3.97 & 7.41 & 29.42 & & & & 1.65 & 4.35 & 7.19 & 36.60 \\
\hline Amphipoda & 1.08 & 5.56 & 6.02 & 1.01 & 5.41 & 5.43 & 1.65 & 8.70 & 14.37 & 25.82 \\
\hline Centric diatom & & & & 2.01 & 10.81 & 21.73 & & & & 21.73 \\
\hline Crustacean part & & & & 1.01 & 5.41 & 5.43 & 3.31 & 4.35 & 14.37 & 19.81 \\
\hline Cladocera & 1.08 & 5.56 & 6.02 & 1.51 & 8.11 & 1222 & & & & 18.24 \\
\hline Cumacea & & & & & & & 1.65 & 8.70 & 14.37 & 14.37 \\
\hline Crustacean mauplius & 1.44 & 5.56 & 8.02 & 1.01 & 2.70 & 2.72 & & & & 10.74 \\
\hline Pennate diatom & 2.53 & 3.70 & 9.36 & & & & & & & 9.36 \\
\hline Copepod unk & & & & & & & 1.65 & 4.35 & 7.19 & 7.19 \\
\hline Isopoda & & & & 1.01 & 5.41 & 5.43 & & & & 5.43 \\
\hline Ostracoda & & & & 1.01 & 5.41 & 5.43 & & & & 5.43 \\
\hline Sponge spicule & 1,81 & 1.85 & 3.34 & & & & & & & 3.34 \\
\hline Copepod egg sac & & & & 1.01 & 2.70 & 2.72 & & & & 2.72 \\
\hline
\end{tabular}


Table 3. Food items making up more than $1 \%$ of the total items $(\mathrm{N})$ in the guts of spotted seatrout larvae by size class. Food iterns are listed in descending order of overall importance. (F) Frequency of occurrence and (IRI) index of relative importance $=$ $\% \mathrm{~N} \times \% \mathrm{~F}$

\begin{tabular}{|c|c|c|c|c|c|c|c|c|c|c|}
\hline \multirow{2}{*}{$\begin{array}{l}\text { Size class (mm SL) } \\
\text { Food Items }\end{array}$} & \multicolumn{3}{|c|}{$<2.99$} & \multicolumn{3}{|c|}{$3.0<\mathrm{SL}<4.5$} & \multicolumn{3}{|c|}{$>4.5$} & \multirow[t]{2}{*}{ Sum of IRI } \\
\hline & $\% \mathrm{~N}$ & $\% F$ & IRI & $\% \mathrm{~N}$ & $\% \mathrm{~F}$ & IRI & $\% \mathrm{~N}$ & $\% \mathrm{~F}$ & IRI & \\
\hline Calanoid copepod & 6.12 & 19.30 & 118.03 & 17.39 & 28.21 & 490.52 & 25.53 & 63.64 & 1624.76 & 2233.31 \\
\hline Bivalve larvae & 14.68 & 31.58 & 463.54 & 6.76 & 25.64 & 173.42 & 10.64 & 18.18 & 193.42 & 830.39 \\
\hline Gastropod viliger & 10.70 & 24.56 & 262.89 & 4.83 & 20.51 & 99.10 & 8.51 & 27.27 & 232.11 & 594.09 \\
\hline Copepod nauplius & 11.62 & 29.82 & 346.59 & 6.76 & 23.08 & 156.08 & 2.13 & 9.09 & 19.34 & 522.00 \\
\hline Dinoflagellate & 9.48 & 21.05 & 199.58 & 8.21 & 17.95 & 147.40 & 2.13 & 9.09 & 19.34 & 366.33 \\
\hline Soft-bodied organism ${ }^{a}$ & 3.06 & 14.04 & 42.92 & 7.73 & 25.64 & 198.19 & 4.26 & 18.18 & 77.37 & 318.48 \\
\hline Copepod egg sac & & & & & & & 10.64 & 27.27 & 290.14 & 290.14 \\
\hline Barnacle cypris & 5.81 & 14.04 & 81.55 & 8.21 & 10.26 & 84.23 & 4.26 & 9.09 & 38.68 & 204.47 \\
\hline Invertebrate egg/cyst ${ }^{\mathrm{b}}$ & 5.50 & 14.04 & 77.26 & 6.76 & 5.13 & 34.68 & 2.13 & 9.09 & 19.34 & 131.28 \\
\hline Foraminifera & 5.50 & 15.79 & 86.91 & 1.93 & 7.69 & 14.86 & & & & 101.78 \\
\hline Copepod unk & 1.83 & 8.77 & 16.10 & 1.45 & 5.13 & 7.43 & 6.38 & 9.09 & 58.03 & 81.55 \\
\hline Barnacle nauplius & 3.98 & 15.79 & 62.77 & 2.42 & 5.13 & 12.39 & & & & 75.16 \\
\hline Cyclopoid copepod & 1.22 & 5.26 & 6.44 & 5.80 & 7.69 & 44.59 & 2.13 & 9.09 & 19.34 & 70.37 \\
\hline Tintinnid & 5.20 & 12.28 & 63.84 & & & & & & & 63.84 \\
\hline Sponge spicule & & & & & & & 6.38 & 9.09 & 58.03 & 58.03 \\
\hline Protozoa & & & & 5.31 & 7.69 & 40.88 & & & & 40.88 \\
\hline Crustacean unk & & & & & & & 4.26 & 9.09 & 38.68 & 38.68 \\
\hline Crustacean nauplius & 1.83 & 10.53 & 19.31 & & & & 2.13 & 9.09 & 19.34 & 38.66 \\
\hline Nematoda & & & & 1.45 & 5.13 & 7.43 & 2.13 & 9.09 & 19.34 & 26.77 \\
\hline Invertebrate egg sac & & & & & & & 2.13 & 9.09 & 19.34 & 19.34 \\
\hline Polychaete & & & & & & & 2.13 & 9.09 & 19.34 & 19.34 \\
\hline Rotifera & & & & & & & 2.13 & 9.09 & 19.34 & 19.34 \\
\hline Diatom & 3.36 & 3.51 & 11.80 & & & & & & & 11.80 \\
\hline Amphipoda & & & & 1.93 & 5.13 & 9.91 & & & & 9.91 \\
\hline Pennate diatom & & & & 1.45 & 5.13 & 7.43 & & & & 7.43 \\
\hline Copepodite & & & & 1.45 & 2.56 & 3.72 & & & & 3.72 \\
\hline Ostracoda & & & & 1.45 & 2.56 & 3.72 & & & & 3.72 \\
\hline Turbellaria & & & & 1.45 & 2.56 & 3.72 & & & & 3.72 \\
\hline
\end{tabular}

Table 4. Percent prey overlap between red drum and spotted seatrout larvae by size-class (mm SL)

\begin{tabular}{|ccccc|}
\hline & Size & $<3.0$ & $\begin{array}{c}\text { Red drum } \\
3.0-4.5\end{array}$ & $>4.5$ \\
\hline Spotted seatrout & $<3.0$ & 65 & 50 & 45 \\
& $3.0-4.5$ & 51 & 67 & 56 \\
& $>4.5$ & 35 & 45 & 44 \\
\hline
\end{tabular}

drum size-class had low overlap with medium and larger larvae. Small red drum (<3.0 mm SL) ate primarily copepod nauplii, bivalve larvae, and barnacle nauplii (Table 2). Medium-sized red drum (3.0 to $4.5 \mathrm{~mm}$ ) ate calanoid copepods, invertebrate eggs, copepod nauplii, and foraminifera; the latter was important only on the surface (Table 6). Large red drum (>4.5 mm) consumed primarily calanoid copepods, dinoflagellates and soft-bodied organisms (may have included flatworms, rotifers, polychaetes, protozoans, tentacles). Soft-bodied organisms were important prey
Table 5. Percent prey overlap between size classes (mm SL) of larvae collected from the surface and bottom of the water column by: (A) red drum, (B) spotted seatrout

\begin{tabular}{|lcccc|}
\hline & \multicolumn{4}{c|}{ Surface } \\
& Size & $<3.0$ & $3.0-4.5$ & $>4.5$ \\
\hline (A) & & & & \\
Bottom & $<3.0$ & 65 & 39 & 39 \\
& $3.0-4.5$ & 37 & 59 & 43 \\
(B) & $>4.5$ & 30 & 52 & 49 \\
Bottom & $<3.0$ & 61 & 45 & 18 \\
& $3.0-4.5$ & 41 & 36 & 23 \\
& $>4.5$ & 35 & 32 & 30 \\
\hline
\end{tabular}

of large red drum in bottom collections and cyclopoid copepods were only important prey in surface collections (Table 6).

There was also high prey overlap in the diets of small spotted seatrout on the surface and bottom but not for the larger size-classes (Table 5B). The most important prey in small spotted seatrout were bivalve larvae, 
Table 6. Important prey items (IPI) identified from the guts of 3 size classes of larvae taken from surface and bottom (6 m) collections in a tidal inlet, Aransas Pass, Texas. (A) red drum and (B) spotted seatrout

\begin{tabular}{|c|c|c|c|}
\hline Size class & $<3 \mathrm{~mm}$ & $3-4.5 \mathrm{~mm}$ & $>4.5 \mathrm{~mm}$ \\
\hline \multicolumn{4}{|l|}{ (A) } \\
\hline \multirow[t]{3}{*}{ Surface } & Copepod nauplij & Calanoid copepod & Calanoid copepod \\
\hline & Barnacle cypris & Foraminifera & Cyclopoid copepod \\
\hline & Bivalve larvae & Invertebrate egg & Dinoflagellate \\
\hline \multirow[t]{3}{*}{ Bottom } & Copepod nauplii & Calanoid copepod & Calanoid copepod \\
\hline & Invertebrate egg & Invertebrate egg & Soft-bodied organism \\
\hline & Barnacle cypris & Copepod nauplii & Dinoflagellate \\
\hline \multicolumn{4}{|c|}{ 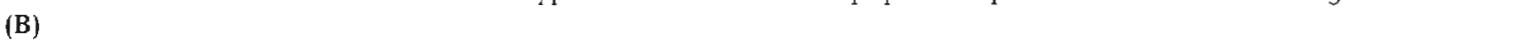 } \\
\hline \multirow[t]{3}{*}{ Surface } & Bivalve larvae & Bivalve larvae & Calanoid copepod \\
\hline & Gastropod viliger & Dinoflagellate & Bivalve larvae \\
\hline & Dinoflagellate & Soft-bodied organism & \\
\hline \multirow[t]{3}{*}{ Bottom } & Copepod nauplii & Calanoid copepod & Calanoid copepod \\
\hline & Bivalve larvae & Soft-bodied organism & Copepod egg sac \\
\hline & Calanoid copepod & Copepad nauplii & Gastropod viliger \\
\hline
\end{tabular}

copepod nauplii, gastropod veligers and dinoflagellates (Table 3), and in medium-sized fish were bivalve larvae, dinoflagellates and soft-bodied organisms on
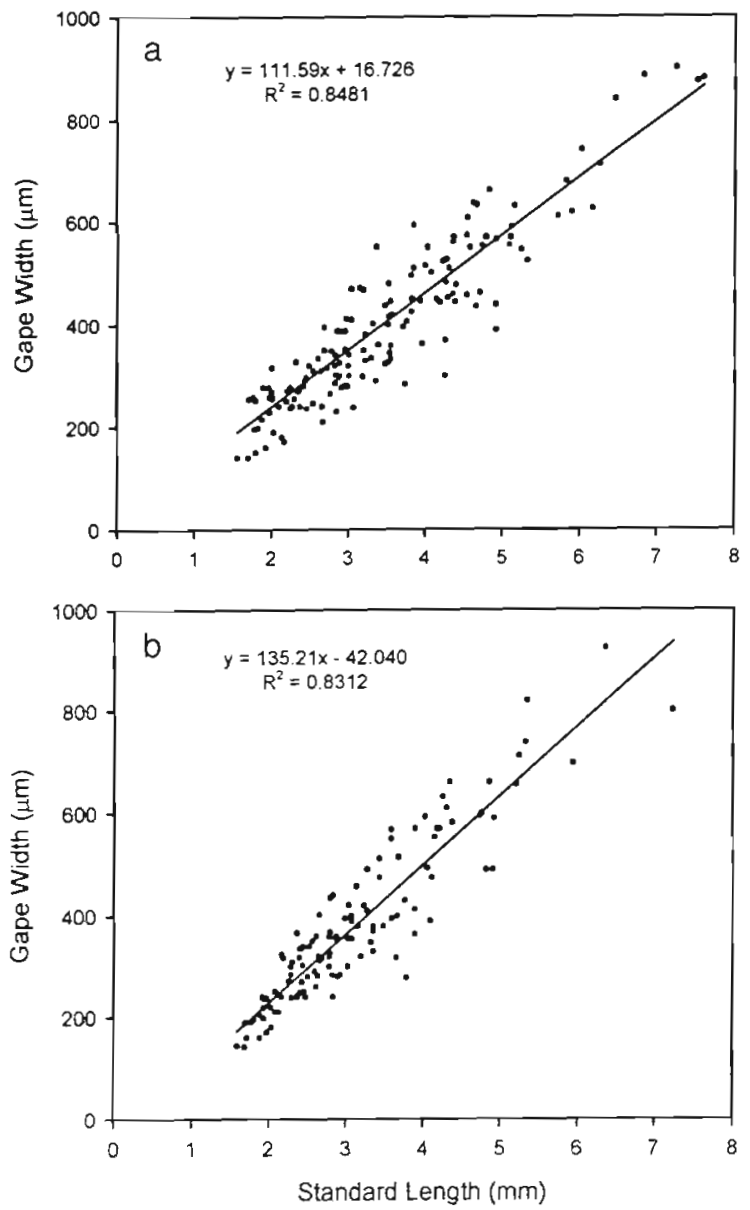

Fig. 2. Relationship of gape width to standard length in (a) red drum and (b) spotted seatrout larvae the surface and calanoid copepods, soft-bodied organisms, and copepod nauplii on the bottom (Table 6). Large spotted seatrout fed on calanoid copepods and bivalve larvae on the surface and calanoid copepods, copepod egg sacs, and gastropod veligers on the bottom.

There was a significant positive correlation of gape size with standard length for both species (Fig. 2). Prey width varied from 10 to $280 \mu \mathrm{m}$ in red drum and 7 to $380 \mu \mathrm{m}$ in spotted seatrout. The regression of individual prey size on gape width was significant (Fig. 3), but only a small portion of the variability was explained by the regression. Small prey were eaten by all sizes of fish; however, there was increasing variability in prey size as a function of length (or growth).

\section{Gut fullness}

The incidence of feeding was high. Only $17 \%$ of all larvae had empty guts, $90 \%$ of those were collected at night. Larvae began to feed after daylight and highest mean gut fullness occurred during midday (12:00 to 20:00 h). Red drum stopped feeding after dark while spotted seatrout fed for 2 more h (Fig. 4). In laboratory studies we found that red drum larvae clear their guts in 2 to $3 \mathrm{~h}$ after the end of feeding (G.J.H. unpubl. data) so reduced gut fullness at midnight reflects termination of feeding between 20:00 and 22:00 h. Sunset declined from 19:50 to 19:10 h during this study. Lowest gut fullness values were found at 04:00 to 06:00 h.

Differences in gut fullness between day and night sampling were highly significant for both species and accounted for the bulk of the variability in both cases (Table 7). Larvae always had significantly fuller guts during the day than at night (Fig. $5 a, b$ ), but there was 

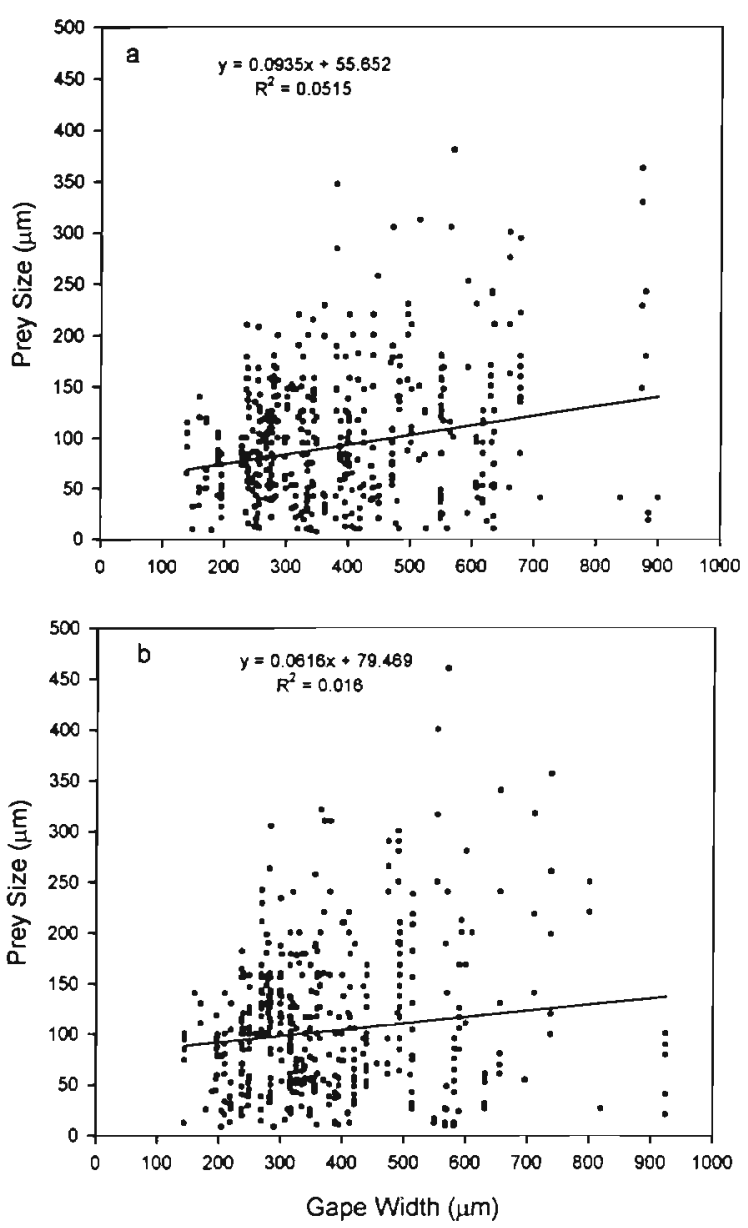

Fig. 3. Relationship between prey size to gape width of each larva in (a) red drum and (b) spotted seatrout

no difference in gut fullness between larvae collected on the surface or bottom (Table 7). The blocking factor trip was significant for red drum but not for spotted seatrout.

Although there was a positive linear relationship between current speed and gut fullness in both red drum and spotted seatrout (Fig. 6), neither regression was significantly different from the mean (red drum, $\mathrm{df}=37, F=1.81, \mathrm{p}=0.187$; spotted seatrout, $\mathrm{df}=33$; $F=1.14 ; \mathrm{p}=0.294$ ). The quadratic fit to the data provided a higher $\mathrm{r}^{2}$ than the comparable linear fit, as expected, but was not significant for either species (red drum, $\mathrm{df}=37, F=1.44, \mathrm{p}=0.249$; spotted seatrout, $\mathrm{df}=33 ; F=1.58 ; \mathrm{p}=0.220$ ).

\section{DISCUSSION}

Early life stages of marine teleost larvae typically feed on microzooplankton with copepod nauplii dominating the diets of first feeding larvae (Hunter 1984).
Copepods were the major prey of red drum and spotted seatrout larvae but both fed on a wide variety of organisms. There were 25 or more food items that made up more than $1 \%$ of the total diet. Size of prey in larval guts was highly variable. A small but significant increase in mean prey size with fish size was accompanied by an increase in maximum prey size but little or no increase in the minimum prey size. The inclusion of abundant but small prey in the diet while adding larger prey as the larva grows assures attainment of minimum ration and stabilizes growth during early life (Houde 1997).

In a study similar to ours, Steen \& Laroche (1983) found a smaller number of prey types in red drum larvae collected in the northcentral Gulf of Mexico off Mississippi. Both studies show copepod nauplii as the major prey of small red drum larvae, however copepod nauplii were found less frequently in the Texas larvae. The Mississippi larvae had fewer prey items but fed on tintinnids (Steen \& Laroche 1983) while small Texas larvae had bivalve veligers, foraminifera, dinoflagellates, cypris larvae and gastropod veligers but not tintinnids among other important prey. Medium- and large-sized larvae differed in the 2 studies in the greater variety of prey and the importance of dinoflagellates and soft-bodied organisms found in the Texas study. The differences in diets of red drum larvae from the 2 study areas in the Gulf of Mexico could result from differences in prey availability. We did not collect prey in this study but selective feeding has been reported for red drum (Lyczkowski-Schultz et al. 1988) and for other sciaenid larvae (Govoni et al. 1986) in the northern Gulf of Mexico.

McMichael \& Peters (1989) evaluated prey of young spotted seatrout in Tampa Bay and reported $85 \%$ of

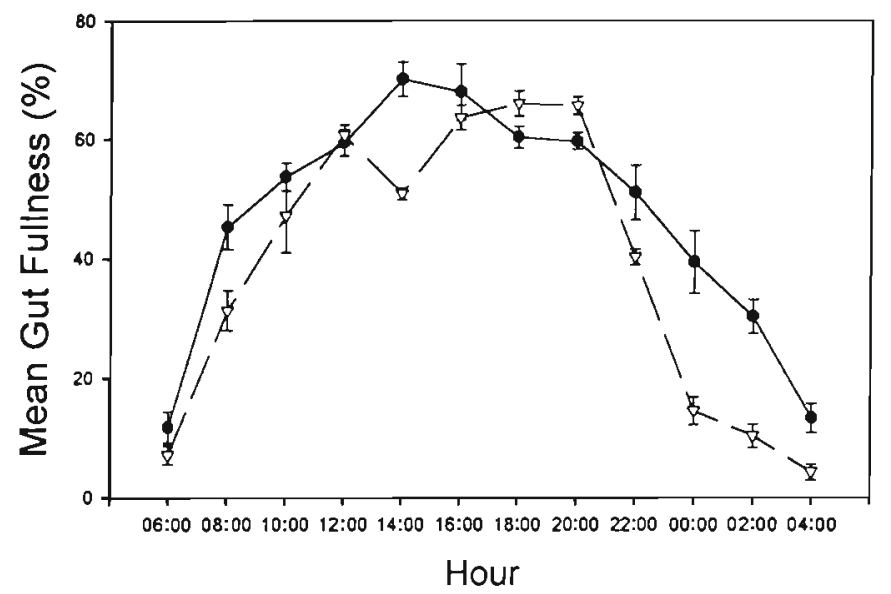

Fig. 4. Mean gut fullness as a function of time for red drum $(-\ldots,, \nabla)$ and spotted seatrout $(-, \bullet)$ larvae. Gut fullness was averaged for all larvae taken at each hour over all collecting trips 
Table 7. Summary of results from randomized block, 2-way ANOVA on arcsine transformed percent gut fullness in red drum and spotted seatrout. The analysis was performed on data from all 4 collection dates for red drum and for the first 2 collection dates for spotted seatrout. ns: not significant

\begin{tabular}{|c|c|c|c|c|c|c|c|c|}
\hline \multirow[b]{2}{*}{ Source } & \multicolumn{4}{|c|}{ Red drum } & \multicolumn{4}{|c|}{ Spotted seatrout } \\
\hline & $\mathrm{df}$ & MS & $F$ & $\mathrm{p}$ & df & MS & $F$ & $\mathrm{p}$ \\
\hline Day-night & 1 & 13.783 & 177.826 & $0.000^{\circ}$ & 1 & 6.7560 & 90.716 & $0.000^{\bullet}$ \\
\hline Depth & 1 & 0.000 & 0.001 & $0.980 \mathrm{~ns}$ & 1 & 0.1770 & 1.565 & $0.213 \mathrm{~ns}$ \\
\hline Trip & 3 & 0.305 & 3.936 & $0.009^{\circ}$ & 1 & 0.0240 & 0.158 & $0.854 \mathrm{~ns}$ \\
\hline Depth vs day-night & 1 & 0.011 & 0.147 & $0.701 \mathrm{~ns}$ & 1 & 0.0004 & 0.050 & $0.823 \mathrm{~ns}$ \\
\hline Error & 205 & 0.078 & 205.000 & & 114 & 0.0740 & 240.909 & \\
\hline
\end{tabular}
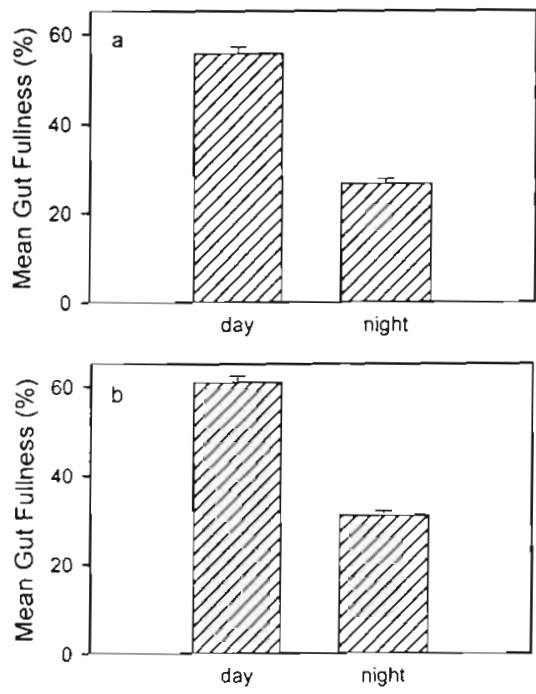

Fig. 5. Mean gut fullness in (a) red drum and (b) spotted seatrout comparing day and night collections. Error bars are $\pm 1 \mathrm{SE}$

larvae had empty guts. They found calanoid copepods were the major prey in the 48 larvae $<8 \mathrm{~mm}$ SL that had food in their guts. Other sciaenid larvae in the Gulf of Mexico including spot Leiostomus xanthurus and Atlantic croaker Micropogonias undulatus also feed primarily on various life stages of calanoid copepods; other important foods reported are tintinnids, pteropods, pelecypods and ostracods (Govoni et al. 1983).

High prey overlap between red drum and spotted seatrout, especially in the small and medium sizeclasses, probably reflects opportunistic feeding on abundant small prey. But it is interesting that bi-valve larvae were more important prey than copepod nauplii in small $(<3.0 \mathrm{~mm}$ SL) spotted seatrout larvae. Gastropod veligers also comprised an important part of the spotted seatrout diet despite the predominance of hard, non-digestible structures in both mollusk larvae. Soft-bodied prey, important in diets of both species,
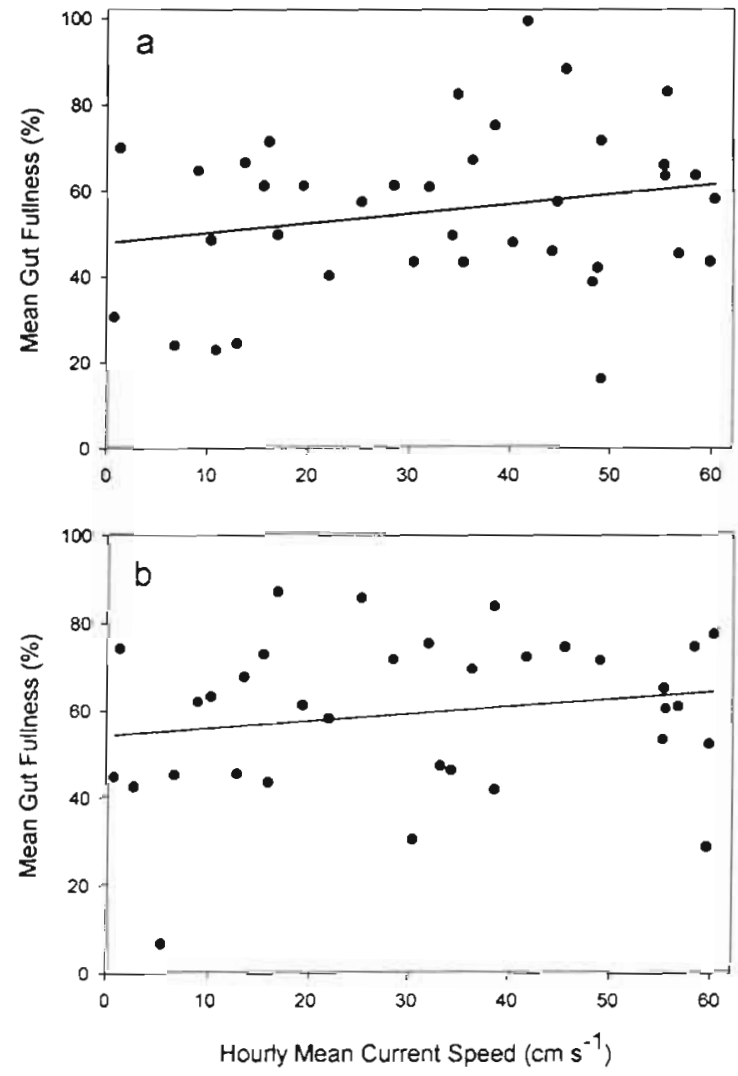

Fig. 6. Relationship between current speed and gut fullness in (a) red drum and (b) spotted seatrout. Each point represents mean gut fullness of all larvae taken in 3 surface and 3 bottom tows during each bi-hourly sample. Current speed is the depth averaged current speed for the hour during which each sample set was taken

have not been reported for other sciaenids and may reflect an abundance of polychaetes, flat worms, or tentacles of benthic organisms in the study site.

The diurnal feeding pattern of red drum and spotted seatrout is typical of other marine fish larvae (Hunter 1984) and is consistent with activities of visual foragers 
(Blaxter 1986, Heath 1992). Red drum larvae show changes in phototactic behavior as they age and grow, but at first feeding they are able to phototactically respond to extremely low light levels (Stearns et al. 1994). The mid-afternoon light intensity near the bottom at $6 \mathrm{~m}$ in Lydia Ann Channel is reported to be 35 to 350 times higher than the estimated intensity threshold for visual feeding in red drum larvae (Stearns et al. 1994). The lack of a significant difference in gut fullness of larvae from surface and bottom collections supports the idea that there is sufficient light throughout the water column for visual predation during daylight hours.

Vertical distribution of larvae in the water column was distinct with the majority found on the bottom during the day, and similar numbers on the surface and bottom at night. This can be interpreted as diurnal movement of larvae away from the surface during the day. An alternative explanation is daytime gear avoidance on the surface. However, larvae did not consistently avoid the net during daylight since more red drum larvae were collected on the surface than on the bottom at 18:00 h.

Contrary to our findings, Lyczkowski-Schultz \& Steen (1991) found red drum larvae in the northcentral Gulf of Mexico to be concentrated higher in the water column during the day than at night. They reported relatively high prey densities throughout the water column and could not attribute the vertical distribution of red drum to microzooplankton abundance (Lyczkowski-Schultz \& Steen 1991). Although fish larvae can vertically migrate in response to prey distribution patterns (Heath 1992), we found little evidence for this; larvae were well fed in both surface and bottom samples. Temperature and salinity profiles showed the water column during this study was well mixed, which should result in homogeneous distribution of microzooplankton.

Tidal currents in shallow waters can produce substantial turbulence (Veth 1990, Fox et al. 1999) and predator-prey encounter rates can increase under such conditions (MacKenzie \& Leggett 1991, Muelbert et al. 1994). Although we were not explicitly testing the 'turbulence theory' (Rothschild \& Osborne 1988) these data provided the opportunity to look for such a trend. Current speed, however, had no significant affect on feeding rates in either species in this study These results concur with recent results of Dower et al. (1997) and Fox et al. (1999), who did not see a functional response of feeding success to increased turbulence. Both red drum and spotted seatrout larvae were very successful at feeding under all conditions with little indication that vertical distribution was associated with feeding success. This supports earlier findings that vertical movement of red drum larvae are cued by tidal or diurnal cycles (Holt et al. 1989) rather than driven by feeding-related vertical migration. Transit periods through well-mixed tidal inlets may provide excellent feeding opportunities, as well as a route to transport larvae to essential nursery habitats.

Acknowledgements. We gratefully acknowledge the invalu able contributions of P. L. Pickering for larval gut identifications and measurements, and $C$. Pratt, who organized the field work and sorted and identified fish larvae. S. Z. Herzka and J. P. Lazo reviewed the manuscript and made valuable suggestions to improve it. This work was supported by a grant from NOAA Office of Sea Grant, Department of Commerce under Grant no. NA89AA-D-SG139 to Texas College Sea Grant Program. This is contribution number 1125 of The University of Texas at Austin Marime Science Institute.

\section{LITERATURE CITED}

Blaxter JHS (1986) Development of sense organs and behavior of teleost larvae with special reference to feeding and predator avoidance. In: Kendall RL (ed) Trans Am Fish Soc 115:98-114

Boehlert GW, Mundy BC (1988) Roles of behavior and physical factors in larval and juvenile fish recruitment to estuarine nursery areas. Am Fish Soc Sym 3:51-67

Dower JF, Miller TJ, Leggett WC (1997). The role of microscale turbulence in the teeding ecology of larval fish. Adv Mar Biol 31:170-221

Fortier L, Leggett WC (1983) Vertical migration and transport of larval fish in a partially mixed estuary. Can Fish Aquat Sci Tech Rep 40(10):1543-1555

Fox CJ, Harrop R. Wimpenny A (1999) Feeding ecology of herring (Clupea harengus) larvae in the turbid Blackwater Estuary. Mar Biol 134:353-365

Govoni JJ, Hoss DE, Chester AJ (1983) Comparative feeding of three species of larval fishes in the northern Gulf of Mexico: Brevoortia patronus, Leiostomus xanthurus, and Micropogonias undulatus. Mar Ecol Prog Ser 13: 189-199

Govoni JJ, Ortner PB, Al-Yamani F, Hill LC (1986) Selective feeding of spot Leiostomus xanthurus and Atlantic croaker Micropogonias undulatus larvae in the northern Gulf of Mexico. Mar Ecol Prog Ser 28:175-183

Heath MR (1992) Field investigations of the early life stages of marine fish. In: Blaxter JHS, Southerland AJ (eds) Adv Mar Biol, Vol 28. Academic Press, London, p 1-174

Hjort J (1914) Fluctuations in the great fisheries of northern Europe viewed in light of biological research. Rapp PV Reun Cons Int Explor Mer 20:1-228

Holt SA, Holt GJ, Young-Abel L (1988). A procedure for identifying sciaenid eggs. Cont Mar Sci (Supp)30:99-108

Holt SA, Holt GJ, Arnold CR (1989) Tidal stream transport of larval fishes into non-stratified estuaries. Rapp PV Reun Cons Int Explor Mer 191:100-104

Houde ED (1987) Fish early life dynamics and recruitment variability. Am Fish Soc Sym 2:17-29

Houde ED (1997) Patterns and consequences of selective processes in teleost early life histories. In: Chambers RC, Trippel EA (eds) Early life history and recruitment in fish populations. Chapman \& Hall, London, p 173-1.96

Hunter JR (1984) Feeding ecology and predation of marine fish larvae. In: Lasker R (ed) Marine fish larvae. University of Washington Press, Seattle, p 33-77 
Leggett W, DeBlois E (1994) Recruitment in marine fishes: is it regulated by starvation and predation in the egg and larval stages? Neth J Sea Res 32:119-134

Litvak MK, Leggett WC (1992) Age and size-selective predation on larval fishes: the bigger-is-better hypothesis revisited. Mar Ecol Prog Ser 81:13-24

Lyczkowski-Shultz J, Ruple DL, Richardson SL, Cowan JH Jr (1990) Distribution of fish larvae relative to time and tide in a Gulf of Mexico barrier island pass. Bull Mar Sci $46(3): 563-577$

Lyczkowski-Shultz J, Steen JP (1991) Diel vertical distribution of red drum (Sciaenops ocellatus) larvae in the northcentral Gulf of Mexico. Fish Bull 89:631-641

Lyczkowski-Shultz J, Steen JP Jr, Comyns BH (1988) Early life history of red drum (Sciaenops ocellatus) in the northcentral Gulf of Mexico. Final Report, Mississippi-Alabama Sea Grant Consortium, NA85AA-D-SG005

MacKenzie BR, Leggett WC (1991) Quantifying the contribution of small-scale turbulence to the encounter rates between larval fish and their zooplankton prey: effects of wind and tide. Mar Ecol Prog Ser 73:149-160

MacKenzie BR, Miller TJ, Cyr SP, Leggett WC (1994) Evidence for a dome-shaped relationship between turbulence and larval fish ingestion rates. Limnol Oceanogr 39: $1790-1799$

McMichael RH Jr, Peters KM (1989) Early life history of spotted seatrout, Cynoscion nebulosus (Pisces: Sciaenidae), in Tampa Bay, Florida. Estuaries 12:98-110

Muelbert JH, Lewis MR, Kelley DE (1994) The importance

Editorial responsibility: Kenneth Sherman (Contributing Editor), Narragansett, Rhode Island, USA of small-scale turbulence in the feeding of herring larvae. J Plankton Res 16:927-944

Munk P, Kiorboe T, Christensen V (1989) Vertical migrations of herring Clupea harengus larvae in relation to light and prey distribution. Environ Biol Fish 26:87-96

Rooker JR, Holt SA, Soto MA, Holt GJ (1998) Post-settlement patterns of habitat use by sciaenid fishes in subtropical seagrass meadows. Estuaries 21:318-327

Rothschild BJ, Osborn TR (1988) Small-scale turbulence and plankton contact rates. J Plankton Res 10:465-474

Smith NP (1979) Tidal dynamics and low-frequency exchanges in the Aransas Pass, Texas. Estuaries 2:218-227

Smith NP, Stoner AW (1993) Computer simulation of larval transport through tidal channels: role of vertical migration. Estuar Coast Shelf Sci 37:43-58

Schoener TW (1968) The anolis lizards of Bimini: resource partitioning in a complex fauna. Ecology 49:704-726

Stearns DE, Holt GJ, Forward RB, Pickering P (1994) Ontogeny of phototactic behavior in red drum larvae (Sciaenidae: Sciaenops ocellatus) Mar Ecol Prog Ser 104:1-11

Steen JP Jr, Laroche JL (1983) The food of red drum (Sciaenops ocellatus) larvae and early juveniles taken from Mississippi Sound and the northern Gulf of Mexico. In: Shabica SV, Cofer NB, Cake EW Jr (eds) Proceedings of the northern Gulf of Mexico estuaries and barrier islands research conference. 13-14 June 1983. Biloxi, MS. US Dept Int Natl Park Serv. SE Reg Off, Atlanta, GA, p 35-38

Veth $C(1990)$ Turbulence measurements in the tidally mixed Southern Bight of the North Sea. Neth J Sea Res 25:301-330

Submitted: March 31, 1999; Accepted: September 13, 1999 Proofs received from author(5): February 2, 2000 